\title{
The Burden of Seizures in Children
}

Can. J. Neurol. Sci. 2004; 31: 3-4

In this issue of the Canadian Journal of Neurological Sciences, Kozyrskyj and Prasad report "The burden of seizures in Manitoba children: a population based study". ${ }^{1}$ The authors use a variety of provincial healthcare administrative datasets to assemble their data. These included registration files of all individuals eligible to receive insured health services, physician billing/reimbursement records, hospitalization discharge records and, most importantly for their study's completeness, prescription records of retail pharmacies submitted for reimbursement under the mandate of existing provincial drug insurance plans. These data sets have been linked and anonymized to ensure privacy and collectively comprise the population health research data repository at the University of Manitoba.

Using this population based approach, age specific prevalence rates were ascertained for children in Manitoba and variations in this rate on the basis of urban or rural residence or socio-economic status evaluated. Specifically, a prevalence rate for seizure disorders of 4.72 per 1,000 children overall was determined varying from 3.5 per 1,000 in children less than five years of age to 7.2 per 1,000 youth age $15-19$ years. A key finding was the observation that in urban areas the treatment prevalence for seizure disorders had an inverse relationship with socio-economic status. This relationship manifested a gradient of increasing prevalence as neighborhood income levels declined. The magnitude of this relationship was such that children in the lowest income quintile (bottom 20\%) were twice as likely as children in the highest income quintile to have seizure disorders. This socio-economic gradient was not noted in rural populations. A difference between urban and rural specific treated prevalence rates was also not detected.

The first aspect of Kozyrskyj and Prasad's study that merits comment are the methods used by the authors to obtain the data presented. Population-based healthcare administrative datasets, created to manage the mechanics and economics of the healthcare system, provide an ongoing reflection of healthcare utilization. $^{2}$ This provides to investigators a mechanism to capture information regarding disease and its evolution. Frequency of occurrence, patterns of disease frequency, possible risk factors, co-morbidities, interventions offered and their impact on disease can be measured and tracked in large groups. ${ }^{3}$ The inclusiveness of the Canadian medicare system, with a single third party payer, together with the introduction of provincial prescription drug coverage, renders a unique opportunity in the Canadian milieu to conduct health service utilization population-based research. ${ }^{4}$ To ensure accuracy, comprehensiveness and relevance, the design and implementation of these datasets should be a cooperative effort featuring not just administrative input but also substantial input from physicians and academics. Needless to say, privacy safeguard needs for individual health records that comprise these large datasets must be an integral feature. The work of Kozyrskyj and
Prasad should be extended to other neurologic conditions across the lifespan to capture population wide impact. Such information will be of critical importance as we lobby for healthcare resources and research funds to be allocated to neurologic conditions in an era of general economic restraint.

The second aspect of the study that merits comment relates to the concept of "burden". The word "burden" can be defined as something which is "carried" or a "difficult responsibility". Synonyms include "load", "duty" or "problem". The word conveys an image of oppression, of shoulders bent or slumped forward under a weight that cannot be removed or lightened.

Kozyrskyj and Prasad's article capture but one aspect of the "burden" of seizure disorders - its numerical aspect." The perspective of burden varies - individual, familial and societal. It may feature limitations on participation and the realization of inherent potential or economic costs, either direct of indirect. ${ }^{6}$ The magnitude of the burden that results also varies between individuals and families affected. The actual extent of these burdens may relate to intrinsic medical factors, but more commonly represent a dynamic interplay with a variety of familial, cultural, educational and societal factors. ${ }^{7}$

Recognition of the existence of burden is but the first step. Its impact must be assessed and accurately measured. Global measures may suffice but often disease specific measures such as the recently developed Canadian quality of life measure in pediatric epilepsy may be necessary. ${ }^{8}$ Such measures may be a more relevant and meaningful way of assessing the effectiveness of our interventions rather than simply counting seizure frequency. ${ }^{9}$

Once burdens are identified and measured, our obligations as health professionals are to minimize their impact and promote the health and well-being of those affected. As noted by Kozyrskyj and Prasad, burdens are disproportionally distributed in society with a socio-economic gradient noted for pediatric seizure disorders. This, together with the varying levels at which burdens operate, suggests that efforts to alleviate burdens must extend beyond the merely medical (i.e. anticonvulsants) to include partners in the rehabilitation, nursing, educational and social milieu. The latter is the most challenging given our rudimentary understanding of the relationship of social factors to disease occurrence and the complexity of factors that will likely require modification to effect substantial change. ${ }^{10}$ Our response to this considerable challenge will be the true measure of our compassion and dedication to these young patients and their families.

Michael I. Shevell

Montreal, Quebec

\section{ACKNOWLeDGeMents}

MIS is a Chercheur Boursier Clinicien (Clinical Research Scholar) of the FRSQ. MIS is also grateful for the support of the MCH Foundation during the preparation of this manuscript and the secretarial assistance of Alba Rinaldi. 


\section{REFERENCES}

1. Kozyrskyj AL, Prasad AN. The burden of seizures in Manitoba children: a population-based study. Can J Neurol Sci 2004;31:4852 .

2. Robinson JR, Young TK, Roos LL, Gelskey DE. Estimating the burden of disease: comparing administrative data and selfreports. Med Care 1997;35:932-947.

3. Kozyrskyj AL, Hildes-Ripstein GE. Assessing health status in Manitoba children: acute and chronic conditions. Can J Public Health 2002;93 Suppl 2:S44-S49.

4. Kozyrskyj AL, Mustard CA. Validation of an electronic, populationbased prescription database. Ann Pharmacother 1998;32: 11521157

5. Cowan LD, Levition A, Bodensteiner JB, Doherty L. Problems in estimating the prevalence of epilepsy in children: the yield from different sources of information. Paediatr Perinat Epidemiol $1989 ; 3: 386-401$
6. Begley CE, Beghi E. The economic cost of epilepsy: a review of the literature. Epilepsia 2002;43 Suppl 4:3-9.

7. Ronen GM, Rosenbaum P, Law M, Streiner DL. Health-related quality of life in childhood epilepsy: the results of children's participation in identifying the components. Dev Med Child Neurol 1999;41:554-559.

8. Ronen GM, Streiner DL, Rosenbaum P, and the Canadian Pediatric Epilepsy Network. Health-related quality of life in children with epilepsy: development and validation of self-report and parent proxy measures. Epilepsia 2003;44:598-612.

9. Ronen GM, Streiner DL, Rosenbaum P. Health-related quality of life in childhood epilepsy: moving beyond 'seizure control with minimal adverse effects'. Health and Quality of Life Outcomes 2003;1:36.

10. Mustard CA, Derksen S, Berthelot JM, Wolfson M, Roos LKL. Age-specific education and income gradients in morbidity and mortality in a Canadian province. Soc Sci Med 1997;45:383-397. 